\title{
Autoinflation: an effective nondrug intervention for glue ear
}

\author{
Chris Del Mar MD, Tammy Hoffmann PhD
}

See also page 961 and www.cmaj.ca/lookup/doi/10.1503/cmaj.141608

I $\mathrm{n}$ a linked research paper, Williamson and colleagues ${ }^{1}$ evaluated the effect of autoinflation, by nostril, of a purpose-designed rubber balloon in 320 children aged 4-11 years with glue ear. Glue ear (also known as secretory otitis media or otitis media with effusion) affects as many as $80 \%$ of children, with peaks in incidence at two and five years of age. ${ }^{2}$ The consequent deafness may interfere with language acquisition, behaviour and education, which worries parents of affected children. Effective treatment options are few.

One of the main findings of the linked study is that glue ear had resolved - by objective measurement using tympanometry — at three months in a greater proportion of children in the intervention group than in the control group. The number needed to treat was only nine. The objective outcome measure was important in this trial because participants could not be masked to allocation. The intention-to-treat analysis also showed improvements in the quality of life of children in the intervention group at three months. Possible adverse effects were common colds and earaches, with a slightly higher number of these among the children who used autoinflation. Child and parent acceptance of the intervention was good, with a compliance rate of $80 \%$ at three months.

At last, there is something effective to offer children with glue ear other than surgery. Surgical insertion of grommet ventilation tubes through the tympanic membrane is immediately effective, as shown by a Cochrane review involving 1728 participants in 10 trials. ${ }^{3}$ However, it has no benefit beyond six months, at which time the deafness of most children in the control groups resolves naturally, and no effect has been shown on the important outcomes of speech and language development. ${ }^{3}$

This important trial by Williamson and colleagues effectively addresses the lack of medical treatments for glue ear available to primary care clinicians. Clinicians are often tempted to use antibiotics in children with glue ear in the futile hope that they might help. A Cochrane systematic review involving 3027 children in 23 studies found that antibiotics are not effective. ${ }^{4}$ Furthermore, unnecessary antibiotic use exposes patients to potential adverse effects ${ }^{5}$ and contributes to the development of antibiotic resistance. ${ }^{6}$

Use of autoinflation as a first-line treatment for glue ear may reduce the number of children who need to undergo surgery for grommet tube placement. Some cases will have resolved before surgery (an estimated 1 in 10 if surgery is delayed by three months ${ }^{3}$ ), and some parents who are concerned about the risks of surgery, hospital admission and anesthetic may elect to persevere with autoinflation beyond three months.

Autoinflation is one of a number of effective nondrug interventions typically underrepresented in research and clinical practice. Getting the message to clinicians about effective nondrug treatments is much harder than it is for drug treatments. Furthermore, prescribing nondrug interventions requires clinicians to know the details of the intervention (as opposed to being able to look up details on prescribing information in a pharmacopeia), and many nondrug trials do not describe the interventions in enough detail for them to be used in practice. $^{7}$ In the case of the intervention evaluated in the current trial, once the physician knows about autoinflation and its effectiveness, the device needs to be available for purchase or dispensing, and the physician must know how to use it and be able to instruct the patient and parents in how and when to use it (in the current trial, the prescription was three times per day for three months).

Williamson and colleagues mostly follow the TIDieR (Template for Intervention Description and Replication) guidelines for intervention reporting ${ }^{8}$ and therefore provide most of the

\section{KEY POINTS}

- Glue ear is common, affecting most children, and can interfere with language acquisition and education.

- Effective therapeutic options, other than surgical insertion of grommet ventilation tubes, are few.

- A new trial found that autoinflation is effective, with a number needed to treat of nine.
Competing interests: See end of article.

This article was solicited and has not been peer reviewed.

Correspondence to:

Chris Del Mar, cdelmar@bond.edu.au

CMAJ 2015. DOI:10.1503 /cmaj.150527 
detail that a physician will need to prescribe the intervention. A physician who wishes to prescribe autoinflation might be wise to obtain a balloon device to use for demonstration and might choose to teach a practice nurse to demonstrate the intervention to the parent and child.

To overcome the lack of a pharmacopeia equivalent for effective nondrug interventions, the Royal Australian College of General Practitioners has recently launched the freely available Handbook of Non-Drug Interventions (HANDI) (www.racgp.org.au/handi). Autoinflation is an intervention that will soon be included in HANDI. Inclusion in this resource will mean that physicians will be able to access details about this nondrug intervention in future, long after reading the article by Williamson and colleagues.

\section{References}

1. Williamson I, Vennik J, Harnden A, et al. Effect of nasal balloon autoinflation in children with otitis media with effusion in primary care: an open randomized controlled trial. CMAJ 2015 July 27 [Epub ahead of print].

2. Zielhuis G, Rach G, Van Den Broek P. Screening for otitis media with effusion in preschool children. Lancet 1989;333: $311-4$.

3. Browning GG, Rovers MM, Williamson I, et al. Grommets (ventilation tubes) for hearing loss associated with otitis media with effusion in children. Cochrane Database Sys Rev 2010;(10):CD001801.
4. van Zon A, van der Heijden GJ, van Dongen T, et al. Antibiotics for otitis media with effusion in children. Cochrane Database Sys Rev 2012;(9):CD009163.

5. Gillies M, Ranakusuma A, Hoffmann T, et al. Common harms from amoxicillin: a systematic review and meta-analysis of randomized placebo-controlled trials for any indication. CMAJ 2015;187:E21-31.

6. Costelloe C, Metcalfe C, Lovering A, et al. Effect of antibiotic prescribing in primary care on antimicrobial resistance in individual patients: systematic review and meta-analysis. BMJ 2010;340:c2096.

7. Hoffmann TC, Erueti C, Glasziou PP. Poor description of nonpharmacological interventions: analysis of consecutive sample of randomised trials. BMJ 2013;347:f3755.

8. Hoffmann TC, Glasziou PP, Boutron I, et al. Better reporting of interventions: template for intervention description and replication (TIDieR) checklist and guide. BMJ 2014;348:g1687.

Affiliation: Centre for Research in Evidence Based Practice, Bond University, Gold Coast, Queensland, Australia

Contributors: Both authors wrote and revised the article, gave final approval of the version to be published and agreed to act as guarantors of the work.

Competing interests: Chris Del Mar has received personal fees from Key Pharmaceuticals for consultancy about a new product (topical analgesia for acute otitis media), personal fees from GlaxoSmithKline Pharmaceuticals for consultancy about a proposed vaccine for otitis media, and grants from the National Health and Medical Research Council and the National Institute for Health Research. He is also the coordinating editor of the Cochrane Acute Respiratory Infections Group. Tammy Hoffmann reports personal fees from the Royal Australian College of General Practitioners as a member of the Handbook of Non-Drug Interventions (HANDI) committee, and is a member of the team that authored the TIDieR (Template for Intervention Description and Replication) checklist.

\section{A credit to you!}

CMA members can earn CME credits for reading CMAJ articles

The CMAJ is committed to helping meet your accredited learning goals. CMA members can earn CME credits simply by reading the CMAJ. Selected CMAJ articles are eligible for Mainpro-M1 credits from The College of Family Physicians of Canada (CFPC). Members can also obtain Mainpro-M2 credits or MOC (Section 2) credits from Royal College of Physicians and Surgeons of Canada (RCPSC) for reading any article in CMAJ.

\section{Learn more}

www.cmaj.ca/site/cme

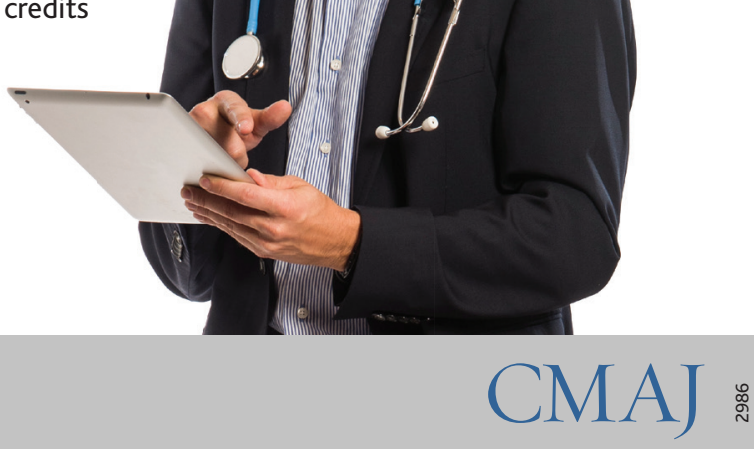

